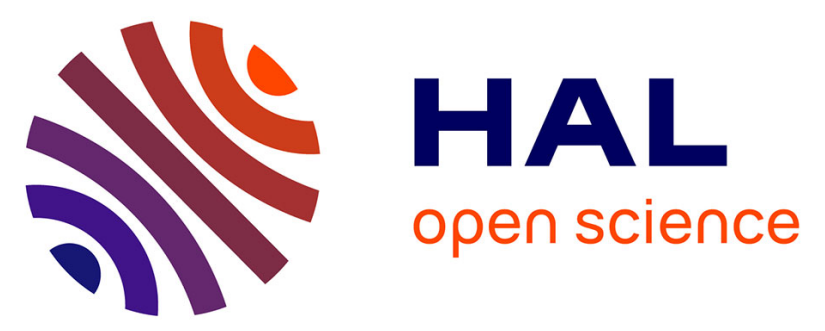

\title{
The influence of age in women in visuo-spatial memory in reaching and navigation tasks with and without landmarks
}

A. Perrochon, A Mandigout, S. Petruzzellis, A Soria Garcia, M. Zaoui, A. Berthoz, J.C. Daviet

\section{To cite this version:}

A. Perrochon, A Mandigout, S. Petruzzellis, A Soria Garcia, M. Zaoui, et al.. The influence of age in women in visuo-spatial memory in reaching and navigation tasks with and without landmarks. Neuroscience Letters, 2018, 684, pp.13 - 17. 10.1016/j.neulet.2018.06.054 hal-01882872

\section{HAL Id: hal-01882872 \\ https://hal-unilim.archives-ouvertes.fr/hal-01882872}

Submitted on 28 May 2021

HAL is a multi-disciplinary open access archive for the deposit and dissemination of scientific research documents, whether they are published or not. The documents may come from teaching and research institutions in France or abroad, or from public or private research centers.
L'archive ouverte pluridisciplinaire HAL, est destinée au dépôt et à la diffusion de documents scientifiques de niveau recherche, publiés ou non, émanant des établissements d'enseignement et de recherche français ou étrangers, des laboratoires publics ou privés. 


\title{
The influence of age in women in visuo-spatial memory in reaching and navigation tasks with and without landmarks
}

\author{
A. Perrochon ${ }^{a, *}$, S. Mandigout
J.C. S. Paviet
a,c \\ a Université de Limoges, HAVAE, EA 6310, F-87000 Limoges, France \\ ${ }^{\mathrm{b}}$ Collège de France, Paris, France \\ ${ }^{\mathrm{C}} \mathrm{CHU}$ Limoges, Hôpital J Rebeyrol, Pôle neuro-sciences tête et cou, Service de médecine physique et de réadaptation, Limoges, France
}

\section{A R T ICL E I N F O}

\section{Keywords:}

Navigation

Visuo-spatial memory

Corsi test

Aging

Landmark

Locomotion

\begin{abstract}
A B S T R A C T
Spatial memory and navigation capabilities tend to decline in normal aging, but few studies have assessed the impact of landmarks on route learning in a large-scale environment. The objectives were to examine age-related effects on visuo-spatial working memory capabilities in various environments and to determine the impact of landmarks in navigation skills in normal aging. 42 young women $(23.6 \pm 4.9$ years $)$ and 37 older women (70.7 \pm 4.7 years) with no cognitive impairment have performed three visuo-spatial working memory tests: one in reaching space (computerized Corsi-Block-Tapping test) and two in locomotor navigation space (a condition without landmarks: Virtual Walking Corsi Test and a condition with landmarks: Virtual Room Walking Test). A two-way mixed ANOVA test showed that the young subjects performed better in all conditions than older subjects. The performance in visuo-spatial working memory thus decreases with age. Visuo-spatial working memory performances were identical in reaching and navigation spaces for both groups. The integration of landmarks into a navigational task decreases performance in older women, while this performance is not altered
in younger women.
\end{abstract}

\section{Introduction}

Many studies have shown age-related deficiencies in various navigational capabilities: learning routes [1-3], topographical memory and orientation [4,5] and cognitive map [6]. The ability to learn complex environments in navigation may require the contribution of cognitive functions, including working memory (WM) [7]. WM seems to be one of the mechanisms underlying the processing of spatial and verbal information which are used to describe the environment in navigation [7].

Visuo-spatial WM has a major role in acquiring spatial information about location, distance, and direction of landmarks and memorizing this information. Visuo-spatial WM can be evaluated in real environment by the Walking Corsi Test (WalCT), which is a large-scale version of the Corsi Block-Tapping Test (CBT) [5,8-10]. The CBT is also a widely-used clinical tool to assess visuo-spatial WM [11]. More recently, another version of the WalCT using the Magic Carpet (MC) has been developed to assess both spatial memory and pathway learning simultaneously [12-14]. These tests consist in reproducing the CBT in a large-scale environment with nine squares placed in the same position as the standard test $(3.9 \times 2.5 \mathrm{~m}$; scale $1: 10$ of the CBT $)$. The subjects must memorize a sequence of locations previously shown by the examiner (WalCT) or by light-emitting diodes or tiles lighting up, remotely controlled by a computer (MC), and then follow a path to reach these locations in the correct order. Several studies have shown that visuo-spatial WM capabilities in navigational tasks were deteriorated in healthy older subjects in comparison to younger subjects $[5,9,14]$. These works on navigational tasks by the WalCT could emphasize the existence of a model that distinguishes a near, or peri-personal, or reaching space (i.e. the portion of space within "grasping distance"), and far, or extrapersonal, or navigational space (i.e. the space beyond arm's reach) $[15,16]$. It was demonstrated that young subjects remember a pathway in navigation space more easily (i.e. WalCT) than in reaching space in delayed recall condition $[10,16]$. Despite the possible role of the type of space (i.e. reaching or navigational spaces) on route learning in normal aging, this aspect yet remains unproven. Abbreviations: WM, working memory; CBT, Corsi block-tapping test; e-CBT, electronic Corsi-block-tapping test; WalCT, Walking Corsi Test; VRWT, Virtual Room Walking Test; VWCT,
Virtual Walking Corsi Test; MC, Magic Carpet * Corresponding author at: Faculté des Sciences et Techniques, Laboratoire Handicap, Activités Vieillissement, Autonomie, Environnement (HAVAE, EA 6310), Université de Limoges,
23 Avenue Albert Thomas, FR-87000 Limoges, France. 
In navigation, landmarks play an important role in guiding navigational behavior and a wide variety of cues exist [17]. A recent study has used the WalCT to test the possible role of spatial language in navigation [18] and has demonstrated that spatial locative comprehension and language capabilities could affect the ability to learn and retrieve navigational information. Moreover, children tend to perform better in route learning when the environment contains landmarks than when there are none [18]. The MC can be used to explore visuospatial WM in aging in navigational tasks by integrating landmarks in the environment.

Finally, gender differences in spatial capabilities and navigational strategies are often reported in the literature $[16,19,20]$. Many studies have shown that women tend to perform better in landmark-based navigation than in an Euclidean-based environment [19,21], but this observation remains to be demonstrated in aging. A new study based on the use of spatial landmarks in a large-scale environment would improve our understanding of women's navigational skills, and even more in the context of aging.

The first objective of our study was to examine the age-related effects on visuo-spatial WM capabilities by differentiating reaching and navigational spaces in a population of women. The second objective was to determine the impact of the presence of landmarks in navigation capabilities in young and older women.

\section{Material and methods}

\subsection{Population}

79 women subjects have participated in this cross-sectional study. The young subjects $(n=42)$ were mostly university students; the older subjects $(\mathrm{n}=37)$ were non-institutionalized volunteers.

The inclusion criteria were the following: a) to be a woman, b) to be over 65 years old for the group of older subjects and under 35 years old for the group of young subjects, c) to be able to walk without assistance, d) to have no language impairment, e) to have normal or corrected-tonormal vision. The exclusion criteria were the following: a) primary visual or hearing impairments, b) history of neurological or psychiatric disease, c) taking medication which could affect gait or balance, d) presence of depressive symptoms or cognitive impairment (MMSE score < 27). All patients gave their written informed consent to participate in this study. The study was approved by the local ethics committee in accordance with the Declaration of Helsinki.

\subsection{Experimental procedure}

Visuo-spatial WM in reaching space was tested using a computerized version of the CBT called e-CBT, while visuo-spatial WM in navigational space was tested using the Virtual Walking Corsi Test (VWCT) which was an environment without landmarks, and the Virtual Room Walking Test (VRWT) which was an environment with landmarks.

\subsubsection{Computerized Corsi Task (e-CBT)}

The subjects performed a computerized version of the CBT called eCBT to assess their visuo-spatial WM (Fig. 1a). Participants were seated next to the experimenter with a portable computer (ASUS Notebook K72Jr Series; Intel Core i5 CPU 2.40 GHz; Windows 7 Home Premium) in front of them. A few differences with the traditional test developed by Philip Corsi (1972) must be noted. First, the e-CBT board was twodimensional because it was displayed on a computer screen (dimensions of the screen: $229 \mathrm{~mm} \times 305 \mathrm{~mm}$, blocks: $22 \mathrm{~mm} \times 22 \mathrm{~mm}$ ) as opposed to the three-dimensional standard board. Although the e-CBT board was slightly smaller than the standard board, the relative block positions were identical. Additionally, the blocks were lit up on the computer as opposed to demonstrated by an experimenter. Despite these differences, the administration procedure of the e-CBT has similar outcomes compared to the traditional CBT [22].
2.2.2. Assessment of navigational task without landmarks: Virtual Walking Corsi Test (VWCT)

We have adapted the manual WalCT to develop a virtual version called VWCT (Fig. 1b). For this test, we have recreated the MC in a virtual version, named the "Virtual Carpet" and developed at the Collège de France, Paris, and which uses a video projector to project a scene on the floor. The VWCT consisted of nine virtual tiles which were embedded within a virtual light grey carpet $(3000 \mathrm{~mm} \times 2400 \mathrm{~mm})$, with the same layout as CBT blocks (scale 1:10). The procedure for the VWCT was identical to the WalCT with the exception that the stimuli were automatically delivered through a video projection system in which virtual tiles are lit up in red by a computer while the patient stands at the starting point, which was symbolized by a tenth physical tile, placed at $1500 \mathrm{~mm}$ outside of the "Virtual Carpet". The subject watched the stimulus, waited for the start signal (computer-delivered beep), and then repeated the sequence.

\subsubsection{Assessment of navigational task with landmarks: Virtual Room} Walking Test (VRWT)

The "Virtual carpet" experimental setup was also used to test locomotor navigation and working memory in a navigational task with landmarks, called the Virtual Room Walking Task (VRWT) and developed at the University of Limoges, France (Fig. 1c). We have used the same "Virtual Carpet" as for the VWCT. This virtual room was made to look like a living room and included nine virtual objects: two sofas with pillow, a houseplant, a bookshelf fitted with books, a desk with paper and pencil, a bookshelf with a phone, a chest of drawers with a pair of glasses on top, a coffee table with a book and a remote control and finally a television cabinet with a TV. Each piece of furniture was introduced to the subject before the beginning of the test by the investigator, who made sure that the subject had a good understanding of the environment.

The VRWT protocol was organized around nine targets like in the eCBT and the VWCT. The targets were small arrows located in front of each of the nine pieces of furniture. A computer briefly highlighted individual pieces of furniture and the corresponding arrow in red in a given sequence. The subject was requested to stand on the starting point and memorize this sequence until the audio signal upon which the subject had to repeat the sequence and walk to the highlighted pieces of furniture. The subject had to stop on the arrow in front of each landmark. The starting point was symbolized by a mat placed at $1500 \mathrm{~mm}$ outside of the virtual room, and subjects had to enter in the virtual environment through a virtual door. In the VRWT, the subjects were instructed not to walk on top of the furniture. For the study protocol, we kept the same room layout during the whole test.

\subsubsection{Procedure}

Participants were tested individually, and e-CBT and navigational tasks were counterbalanced. For the e-CBT and VWCT, the sequences were extracted from the Wechsler Adult Intelligence Scale (WAIS) [23]. The length of the sequence determined the difficulty level, increasing from 2 to 9 . If one out of two trials per sequence length was reproduced correctly by the subject, the sequence length increased by one item [11]. A "span score" was calculated corresponding to the longest sequence the subject was able to correctly reproduce. In e-CBT, the subjects answered by touching the screen, whereas in the navigational task they validated each step of the sequence by standing with both their feet on either the tile for the VWCT or the arrow for the VRWT. In the VRWT, the subjects were not required to face the same direction as the arrow as this would have complicated the task. Each trial was recorded on video to make sure that the subject had walked along the correct sequence.

The spatial memory assessment was set up in an empty room deprived of landmarks. The navigational tasks were based on the "Virtual Carpet", which was projected on the floor by a projector placed at $600 \mathrm{~mm}$ from the border of the virtual space at the opposite of the 


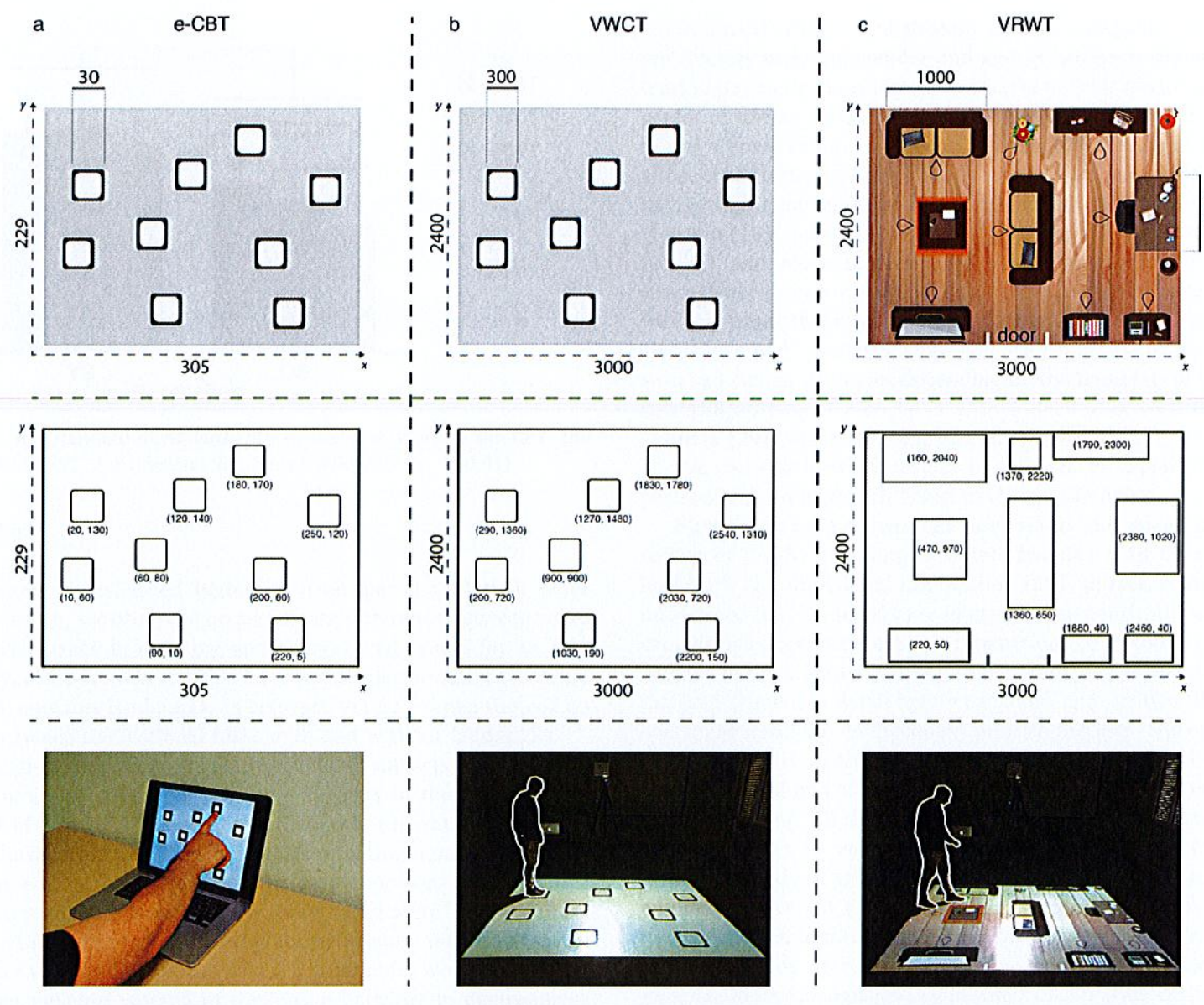
Fig. 1. (a) Electronic Corsi Block Tapping test (e-CBT) condition, (b) Virtual Walking Corsi Test (VWCT), (c) Virtual Room Walking Test (VRWT). Dimensions ii
millimeters. First line: Experimental set--up (subject's ivew; s Second line: The arrangement of objects for each condition with the respective x and y coordinates of the

subject's position, exactly $4500 \mathrm{~mm}$ away from the subject (Subject's $3000 \mathrm{~mm} \times 2400 \mathrm{~mm}$. Before the bejegin of navigational tasks, each subject went through a familiarization phase to verify that they had All the conditions of this study

other of 37 healthy older subjects ( $70.7 \pm 4.7$ years), who performed

A 2-3 mixed factorial ANOVA showed a main age effect [F(1, 78) $=217.3, \quad p=0.0001]$, with young subjects (span score $(\mathrm{M} \pm \mathrm{SD})=6.95 \pm 1.31)$ performing better than older subjects (4.77 \pm .95$)$. A main task eftect was also obseved or task condition $(5.37 \pm 1.20) \pm 1.16, \mathrm{P}<0.05$ ) VWCT $=6.03 \pm 1.16 ; \mathrm{p}<0.05)$.

2.3. Statistical analysis

The Age vs Tasks interaction was statistically significant $(\mathrm{F}(5$, $233)=3.2 ; \mathrm{p}=0.040$ ). Older subjects were less efficient than young $\mathrm{p}<0.01$ ) e-CWTC (respectively $5.32 \pm 0.91$ vs $7.00 \pm 1.10$ $p<0.01)$ and in VRCT (respectively $4.13 \pm 0.94$ vs $6.66 \pm 1.42$. found between task conditions (e-CBT $=7.00 \pm 1.10$ $\mathrm{VWCT}=7.19 \pm 1.40 ; \mathrm{VRCT}=6.66 \pm 1.42 ; \mathrm{p}>0.05$; Fig. 2 ). In the space better results than the landmost (VRWT $=4.13 \pm 0.94 ; \mathrm{p}<0.01 ;$ Fig. 2 ). In contrast, we observed that there was no significant difference in the assessment of visuospatial WM capabilities between reaching space (e-CBT $=5.32$

3. Results

Our study featured a total population of 79 women subjects split Into two groups, one of 42 young subjects ( $23.6 \pm 4.9$ years) and the 


\section{Conclusions}

This study has demonstrated that aging affects visuo-spatial WM capabilities in reaching and navigation spaces. Navigation capabilities seem to decline in older women when landmarks are present in the environment, whereas young women were not affected by the integration of landmarks in space.

We may suppose that the VRWT, as well as others complex walking tasks $[35,36]$, could be used in the early detection of pathologies like dementia, as it has been shown that disorders of spatial orientation were one of its earliest symptoms $[8,26]$.

\section{Conflict of interest}

Authors report no conflict of interest.

\section{Acknowledgments}

Language corrected by Maxime DAVID Traduction.

The "Virtual Carpet" has been developed by Mohamed Zaoui and Alain Berthoz at the College de France in Paris.

\section{References}

[1] S.D. Moffat, A.B. Zonderman, S.M. Resnick, Age differences in spatial memory in a virtual environment navigation task, Neurobiol. Aging 22 (2001) 787-796.

[2] S.M. Wilkniss, M.G. Jones, D.L. Korol, P.E. Gold, C.A. Manning, Age-related differences in an ecologically based study of route learning, Psychol. Aging 12 (1997) 372-375.

[3] S.D. Moffat, Aging and spatial navigation: what do we know and where do we go? Neuropsychol. Rev. 19 (2009) 478-489, http://dx.doi.org/10.1007/s11065-0099120-3.

[4] I. Liu, R.M. Levy, J.J.S. Barton, G. Iaria, Age and gender differences in various topographical orientation strategies, Brain Res. 1410 (2011) 112-119, http://dx. doi.org/10.1016/j.brainres.2011.07.005.

[5] L. Piccardi, F. Bianchini, O. Argento, A. De Nigris, A. Maialetti, L. Palermo, C. Guariglia, The Walking Corsi Test (WalCT): standardization of the topographical memory test in an Italian population, Neurol. Sci. 34 (2013) 971-978, http://dx. doi.org/10.1007/s10072-012-1175-x

[6] G. Iaria, L. Palermo, G. Committeri, J.J.S. Barton, Age differences in the formation and use of cognitive maps, Behav. Brain Res. 196 (2009) 187-191, http://dx.doi. org/10.1016/j.bbr.2008.08.040.

[7] C. Meneghetti, E. Borella, E. Carbone, M. Martinelli, R. De Beni, Environment learning using descriptions or navigation: the involvement of working memory in young and older adults, Br. J. Psychol. Lond. Engl. 1953107 (2016) 259-280, http://dx.doi.org/10.1111/bjop.12145.

[8] F. Bianchini, A. Di Vita, L. Palermo, L. Piccardi, C. Blundo, C. Guariglia, A selective egocentric topographical working memory deficit in the early stages of Alzheimer's disease: a preliminary study, Am. J. Alzheimers Dis. Other Dement. 29 (2014) 749-754, http://dx.doi.org/10.1177/1533317514536597.

[9] L. Piccardi, G. Iaria, F. Bianchini, L. Zompanti, C. Guariglia, Dissociated deficits of visuo-spatial memory in near space and navigational space: evidence from braindamaged patients and healthy older participants, Aging Neuropsychol. Cogn. 18 (2011) 362-384, http://dx.doi.org/10.1080/13825585.2011.560243.

[10] L. Piccardi, G. Iaria, M. Ricci, F. Bianchini, L. Zompanti, C. Guariglia, Walking in the Corsi test: which type of memory do you need? Neurosci. Lett. 432 (2008) 127-131, http://dx.doi.org/10.1016/j.neulet.2007.12.044.

[11] D.B. Berch, R. Krikorian, E.M. Huha, The Corsi block-tapping task: methodological and theoretical considerations, Brain Cogn. 38 (1998) 317-338, http://dx.doi.org/ 10.1006/brcg.1998.1039.

[12] V. Belmonti, G. Cioni, A. Berthoz, Switching from reaching to navigation: differential cognitive strategies for spatial memory in children and adults, Dev. Sci. 18 (2015) 569-586, http://dx.doi.org/10.1111/desc.12240.

[13] T. Meilinger, A. Berthoz, J.M. Wiener, The integration of spatial information across different viewpoints, Mem. Cogn. 39 (2011) 1042-1054.
[14] A. Perrochon, G. Kemoun, B. Dugué, A. Berthoz, Cognitive impairment assessment through visuospatial memory can be performed with a modified walking Corsi test using the "Magic Carpet", Dement. Geriatr. Cogn. Disord. Extra 4 (2014) 1-13, http://dx.doi.org/10.1159/000356727.

[15] F. Nemmi, M. Boccia, L. Piccardi, G. Galati, C. Guariglia, Segregation of neural circuits involved in spatial learning in reaching and navigational space, Neuropsychologia 51 (2013) 1561-1570, http://dx.doi.org/10.1016/j. neuropsychologia.2013.03.031.

[16] L. Piccardi, F. Bianchini, R. Nori, A. Marano, F. Jachini, L. Lasala, C. Guariglia, Spatial location and pathway memory compared in the reaching vs. walking domains, Neurosci. Lett. 566 (2014) 226-230, http://dx.doi.org/10.1016/j.neulet. 2014.03.005.

[17] E. Chan, O. Baumann, M.A. Bellgrove, J.B. Mattingley, From objects to landmarks: the function of visual location information in spatial navigation, Front. Psychol. 3 (2012) 304, http://dx.doi.org/10.3389/fpsyg.2012.00304.

[18] L. Piccardi, L. Palermo, A. Bocchi, C. Guariglia, S. D'Amico, Does spatial locative comprehension predict landmark-based navigation? PLoS One 10 (2015) e0115432, http://dx.doi.org/10.1371/journal.pone.0115432.

[19] D.M. Saucier, S.M. Green, J. Leason, A. MacFadden, S. Bell, L.J. Elias, Are sex differences in navigation caused by sexually dimorphic strategies or by differences in the ability to use the strategies? Behav. Neurosci. 116 (2002) 403-410.

[20] S. Lambrey, A. Berthoz, Gender differences in the use of external landmarks versus spatial representations updated by self-motion, J. Integr. Neurosci. 06 (2007) 379-401, http://dx.doi.org/10.1142/S021963520700157X.

[21] G. Grön, A.P. Wunderlich, M. Spitzer, R. Tomczak, M.W. Riepe, Brain activation during human navigation: gender-different neural networks as substrate of performance, Nat. Neurosci. 3 (2000) 404-408, http://dx.doi.org/10.1038/73980.

[22] R.E. Nelson, A.L. Dickson, J.H. Baños, An automated administration of Corsi's block-tapping test, Percept. Mot. Skills 91 (2000) 578-580, http://dx.doi.org/10. 2466/pms.2000.91.2.578.

[23] D. Wechsler, Wechsler Adult Intelligence Scale, third edition, The Psychological Corporation, San Antonio, 1997.

[24] D. Head, M. Isom, Age effects on wayfinding and route learning skills, Behav. Brain Res. 209 (2010) 49-58, http://dx.doi.org/10.1016/j.bbr.2010.01.012.

[25] J.Y. Zhong, S.D. Moffat, Age-related differences in associative learning of landmarks and heading directions in a virtual navigation task, Front. Aging Neurosci. 8 (2016), http://dx.doi.org/10.3389/fnagi.2016.00122.

[26] I. Iachini, A. Iavarone, V.P. Senese, F. Ruotolo, G. Ruggiero, Visuospatial memory in healthy elderly, AD and MCI: a review, Curr. Aging Sci. 2 (2009) 43-59.

[27] C. Techentin, D. Voyer, S.D. Voyer, Spatial abilities and aging: a meta-analysis, Exp. Aging Res. 40 (2014) 395-425, http://dx.doi.org/10.1080/0361073X.2014. 926773.

[28] T. Hartley, E.A. Maguire, H.J. Spiers, N. Burgess, The well-worn route and the path less traveled: distinct neural bases of route following and wayfinding in humans, Neuron 37 (2003) 877-888.

[29] D. Colombo, S. Serino, C. Tuena, E. Pedroli, A. Dakanalis, P. Cipresso, G. Riva, Egocentric and allocentric spatial reference frames in aging: a systematic review, Neurosci. Biobehav. Rev. 80 (2017) 605-621, http://dx.doi.org/10.1016/j. neubiorev.2017.07.012.

[30] A.K. Thomas, B.M. Bonura, H.A. Taylor, The influence of semantic relationships on older adult map memory, Psychol. Aging 27 (2012) 657-665, http://dx.doi.org/10. $1037 / \mathrm{a} 0028504$

[31] J. Frankenstein, S. Brüssow, F. Ruzzoli, C. Hölscher, The language of landmarks: the role of background knowledge in indoor wayfinding, Cogn. Process. 13 (2012) 165-170, http://dx.doi.org/10.1007/s10339-012-0482-8.

[32] N.E. Andersen, L. Dahmani, K. Konishi, V.D. Bohbot, Eye tracking, strategies, and sex differences in virtual navigation, Neurobiol. Learn. Mem. 97 (2012) 81-89, http://dx.doi.org/10.1016/j.nlm.2011.09.007.

[33] A. Shusterman, S. Ah Lee, E.S. Spelke, Cognitive effects of language on human navigation, Cognition 120 (2011) 186-201, http://dx.doi.org/10.1016/j.cognition. 2011.04.004.

[34] J. Laczó, R. Andel, Z. Nedelska, M. Vyhnalek, K. Vlcek, S. Crutch, J. Harrison, J. Hort, Exploring the contribution of spatial navigation to cognitive functioning in older adults, Neurobiol. Aging 51 (2017) 67-70, http://dx.doi.org/10.1016/j. neurobiolaging.2016.12.003.

[35] A. Perrochon, G. Kemoun, E. Watelain, A. Berthoz, Walking Stroop carpet: an innovative dual-task concept for detecting cognitive impairment, Clin. Interv. Aging 8 (2013) 317-328, http://dx.doi.org/10.2147/CIA.S38667.

[36] A. Perrochon, G. Kemoun, The walking trail-making test is an early detection too for mild cognitive impairment, Clin. Interv. Aging 9 (2014) 111-119, http://dx.doi. org/10.2147/CIA.S53645. 